\title{
Tackling graduate unemployment in North Africa through employment subsidies: A look at the SIVP programme in Tunisia
}

\author{
Stijn Broecke
}

Correspondence: Stijn.Broecke@ OECD.org

Organisation for Economic Cooperation and Development (OECD), Paris, France
Abstract: This paper takes a closer look at Tunisia's SIVP: an employment subsidy aimed at university graduates and, until recently, the country's largest active labour market policy. Using a tracer survey of the 2004 graduating cohort, OLS and matching techniques are applied to estimate the relationship between programme participation and the labour market outcomes of participants. Graduates who benefited from the programme appear less likely to be unemployed and considerably more likely to have found a job in the private sector - but this may partly reflect selection into the programme, which is not random.

JEL classification: J08, J20

Keywords: Graduate unemployment; Employment subsidy; MENA

\section{Introduction}

Graduate unemployment (the problem of unemployment among the university educated) is possibly one of the greatest challenges that governments in North Africa currently face. In 2010/11, at the time of the Arab Spring, around one in five graduates in North Africa were unemployed ${ }^{1}$ In Tunisia, cradle of the revolutions which swept across the MENA region, it is widely believed that graduate unemployment was one of the major causes. Indeed, when Mohamed Bouazizi, a street vendor in the rural town of Sidi Bouzid had set himself on fire on $17^{\text {th }}$ December 2010 (the incident which sparked the Tunisian revolution), he was believed to be an unemployed graduate desperately trying to scrape together a living. ${ }^{2}$ In post-revolution Tunisia, graduate unemployment continues to be a major cause of social unrest, and the new government has made it one of its top priorities.

The causes of graduate unemployment in Tunisia are complex, and both demand and supply factors are at play. On the supply side, previous governments have made heavy investments in education. Tunisia's first president after independence, Habib Bourguiba, made education free and compulsory until the age of 16. Large cohorts of young people completing basic education led, in turn, to the expansion of upper secondary education (partly under pressure of the international donor community) and, because passing the baccalaureate in Tunisia provides automatic entry into higher education, this put pressure on the government to increase the number of university places, which are provided free of charge. As a means of satisfying this popular

(c) 2013 Broecke; licensee Springer. This is an Open Access article distributed under the terms of the Creative Commons Attribution License (http://creativecommons.org/licenses/by/2.0), which permits unrestricted use, distribution, and reproduction in any medium, provided the original work is properly cited. 
demand, higher education experienced a rapid expansion under Tunisia's second president, Zine El Abidine Ben Ali, from fewer than 12,000 graduates in 1993/94 to 86,000 in 2009/10. This seven-fold increase in the number of university graduates came at the expense of quality, and was matched by an equally large increase in the graduate unemployment rate over the same period. In 1994/95, just 3.8\% of graduates were unemployed. By 2009/10, nearly a quarter were. ${ }^{3}$

At the same time, few jobs were being created. The ILO (2011) has estimated that, between 2004 and 2007, there were 77,000 net jobs created - the majority of which were low-skilled. At the same time, the labour force increased by nearly 190,000 and, as pointed out above, included many young university graduates entering the labour market for the first time.

Tackling graduate unemployment in Tunisia will need a multi-pronged approach, including education reforms, private sector development, but also changes in labour market institutions, and a range of active labour market policies to help graduates' transition from education into work. The focus in this paper is on the latter type of policies. More specifically, it looks at the Stage d'Initiation à la Vie Professionelle (Initiation into the World of Work - SIVP), an employment subsidy (or hiring credit) ${ }^{4}$ aimed at incentivising employers to take on first-time job-seekers and, until recently, Tunisia's largest active labour market programme. In 2010, the national SIVP budget was approximately TND 45.5 million (or around EUR 22 million). ${ }^{5}$ The programme has also rapidly grown in size: the number of graduates benefiting from a SIVP has increased from under 15,000 in 2004 to just over 45,000 in 2011 (ANETI 2011).

Given the seriousness of graduate unemployment in Tunisia, the urgency to do something about it, and the importance of the SIVP in the government's employment strategy, an assessment of the programme is timely. Despite the fact that such policies are widely used in the North Africa region (e.g. Idmaj in Morocco and CTA in Algeria), few studies have critically assessed them in any great detail. In one notable exception in the case of Tunisia, Marouani (2010) uses a dynamic general equilibrium model to compare a range of alternative labour market policies, including the SIVP, and concludes that the latter (if targeted at highly skilled intensive sectors) is more effective than tax reductions or investment subsidies at generating jobs, but not enough to reduce unemployment significantly. ${ }^{6}$

More generally, there is little systematic analysis on the effectiveness of active labour market policies in the MENA region (Angel-Urdinola et al. 2010). To a large extent, this is a result of a lack of transparency on the part of previous regimes and an unwillingness to accept criticism of government policies. Today, with post-revolutionary and elected governments in place in a number of these countries, there is a renewed opportunity to change the way policy is made, and make it more evidence-based. Although such evidence is still rare, there are signs that things may be changing. In Tunisia, for instance, a recent paper by Premand et al. (2012) discusses a randomised controlled trial of entrepreneurship training for university graduates. The authors conclude that, although the programme had small effects on the likelihood of self-employment, it had no effect on employment rates overall. This evidence makes it all the more important to explore the effectiveness of other programmes (such as the SIVP) to see which interventions might be effective at tackling graduate unemployment. The purpose of this paper is to help fill this gap in the literature. 
The data used in the paper come from a graduate tracer study (GTS) of a representative sample of over 4,700 university graduates who qualified in 2004 and were interviewed in both 2005 (around one and a half years after graduation) and 2007 (around three and a half years after graduation). This dataset also contains a "calendar" recording monthly activities over the entire period since graduation ( 44 months). The data are not experimental and, as will become clear from the descriptive analysis, selection into the programme is not random. Ordinary Least Squares (OLS) and Propensity Score Matching (PSM) will be used to try and compare treated and untreated individuals. The data allow the investigation of a wide range of outcomes, including joblessness, unemployment, sector of employment, as well as job quality and earnings.

The analysis shows clearly that SIVP beneficiaries have lower joblessness and unemployment rates, and that they are much more likely to be hired in the private sector - although these results cannot be interpreted as causal since the identification strategy used is not strong enough to make such inferences. The paper does highlight some key design aspects of the policy which need to be amended if it is to have a greater impact on the employment rates of graduates. In particular, greater targeting of those graduates facing the highest risk of unemployment would enhance the effectiveness of the programme and reduce the deadweight loss. In addition, it is likely that combining the programme with other interventions (like training, counselling and job search assistance) would also improve its effectiveness (Katz 1996; Kluve 2006).

The paper proceeds as follows. Section 'Employment subsidies' reviews the literature on employment subsidies and summarises their effectiveness in generating employment, as well as the design features associated with the most successful programmes. Section 'The SIVP programme' then explains the workings of the Tunisian SIVP programme at the time the graduates in the dataset were observed. Section 'Data and descriptive statistics' discusses the data and describes the characteristics of SIVP beneficiaries. Section 'Unemployment and participation in the SIVP programme' looks in more detail at the attributes associated with selection into the programme, and Section 'SIVP participation and employment outcomes' provides a brief overview of the methodologies used and presents the results from the analysis. Section 'Discussion and conclusion' concludes, calculates the cost-effectiveness of the programme, and offers some recommendations on how to improve employment subsidies in Tunisia (or, indeed, elsewhere).

\section{Employment subsidies}

The objective of employment subsidies (which usually take the form of either direct subsidies or social security waivers/rebates) is to reduce the cost of hiring new employees and, as a result, increase the demand for labour. They may be particularly useful in the case of young workers, whose productivity is initially unobserved. Risk-averse employers may be reluctant to take on such workers because of the perceived risk of low productivity, and lowering the cost of hiring them may make employers more willing to experiment and take on youth. In particular, in the case of Tunisia, there is an institutional reason why the wages of graduates do not simply adjust downward to account for this risk: the existence of collective wage agreements. Given that the supply of graduates in Tunisia exceeds the demand by quite a margin, wage subsidies are likely to play an important role in raising the attractiveness of graduates to employers, as well as in keeping their jobs formal. 
The evidence on the effectiveness of employment subsidies has been summarised in a number of literature reviews over the years. The assessments have ranged from the very pessimistic ("Expenditures on subsidised jobs seem a waste of money from the perspective of the aggregate labor market outcomes" - Boone and van Ours 2004) to far more positive ones ("Wage subsidies have generally had significant positive effects on improving employment outcomes for youth in transition and developed countries [...] with net employment effects from 12 to 15.6\%" - Betcherman et al. 2007). Most authors, however, conclude that the effect of employment subsidies is positive, albeit modest (Katz 1996; OECD 2005; Kluve 2010; Immervoll and Scarpetta 2012; Neumark 2013; Neumark and Grijalva 2013).

One of the key problems encountered are large deadweight ${ }^{7}$ losses (subsidising jobs which would have been created anyway) as well as substitution effects (hiring subsidised workers instead of non-subsidised ones, with no net employment effect). Evaluations of wage subsidies in Australia, Belgium, Ireland and the Netherlands have suggested combined deadweight and substitution effects amounting to around $90 \%$ (Martin 2000). Similarly, Bartik (2001) estimates that the share of hiring that would have happened in the absence of the employment subsidy frequently exceeds $90 \%$.

That said, some wage subsidy programmes have been estimated to have had large positive effects on employment - such as Argentina's ProEmpleo programme (Betcherman et al. 2004), the New Deal for Young People in the United Kingdom (Van Reenen 2003) and the New Jobs Tax Credit in the United States (Bartik and Bishop 2009). As stated by Betcherman et al. (2004) and Kluve (2010), much of the success of such programmes will depend on their specific design features. Three aspects are particularly important: (i) the degree of targeting; (ii) the extent to which subsidies reward new hiring; and (iii) whether they are part of a more comprehensive package of assistance aimed at the beneficiary. Starting with the latter, it has been shown that subsidies which are twinned with other interventions such as training, counselling and/or job search assistance are often the most effective ones (Katz 1996; Kluve 2006).

In order to avoid/reduce deadweight loss, subsidy programmes often target particular sub-groups, such as the long-term unemployed, or particular geographical areas. Although this has been shown to reduce deadweight loss, one risk is that excessive targeting reduces take-up due to administrative burdens (Martin 2000; Neumark 2013) or stigmatises programme participants (Burtless 1985; Dubin and Rivers 1993).

The best employment subsidies also reward additional hiring only (over and above the ordinary recruitment plans of companies). Again, however, this may become administratively burdensome to monitor, and it may introduce a risk of churning (i.e. continuously hiring new subsidised workers each time the previous subsidies have run out) - Neumark and Grijalva (2013). To avoid churning, conditions are often placed on employers to ensure that they absorb a certain percentage of subsidised workers into their regular headcount before they are allowed to receive any further subsidies. Recouping the subsidies (or part of them) if employment creation is lower than required is another strategy used (Neumark and Grijalva 2013).

Finally, some authors have argued that employment subsidies are most effective if used for short periods, particularly as counter-cyclical tools (Kluve 2006; Neumark 2013). This is partly because they are flexible and can be scaled up relatively quickly. That said, there is often a strong social element to such programmes, and so 
governments frequently persevere with them even if there is no net employment gain (Martin 2000).

\section{The SIVP programme}

The SIVP is an employment subsidy targeting higher education graduates. It was introduced in 1987, and a number of laws, decrees and bylaws have modified the programme since. $^{8}$ What follows is a reconstruction of the structure of the programme at the time that the graduates in the GTS data were observed - based on conversations with relevant parties, the available legal documents, as well as descriptions of the programme on official websites and in government reports.

The subsidy targeted unemployed university graduates who were looking for their first job. To be eligible, the individual needed to have been registered with the public employment service (ANETI) for a period of at least three months. An exception to this rule was made for graduates whose degrees were considered to face particular recruitment difficulties. According to a bylaw published 15 June 1995 these degrees were: agricultural sciences; chemistry; masters in engineering; electrical engineering; manufacturing; civil engineering; mining; law; Arabic; and Islamic studies. ${ }^{9}$

Eligible firms ${ }^{10}$ needed to be registered (i.e. part of the formal sector) and the number of subsidies received depended on the firm's size. Firms with at least 10 permanent staff members were allowed to hire up to $15 \%$ of their workers under the SIVP programme ${ }^{11}$ and firms with fewer than 10 permanent members of staff could hire up to $50 \%$. These proportions were higher $(+10 \%)$ if: (i) firms were located in specially designated regional development areas; or (ii) they hosted graduates whose degrees encountered recruitment difficulties; or (iii) they took on disabled graduates. Firms could only continue to receive new subsidies if, over the last three years, they had recruited at least $25 \%$ of all their subsidised graduates.

The value of the subsidy ranged somewhere between 100 and 250 TND (50 to 125 EUR) depending on the level and the subject of the degree studied, as well as the year of study completed. Undergraduate degrees (or uncompleted graduate degrees) with technical specialisations received 123 TND; those with medical specialisations, 104 TND; and other specialisations, 100 TND. Engineering degrees attracted 145 TND and Masters degrees 107 TND. 145 TND were paid to those with graduate degrees with technical or medical specialisations, and 160 TND to those with architecture or engineering specialisations. Finally, medical degrees (medicine, dental, veterinary, pharmaceutical) received 250 TND. Already one notices that those graduates who were least likely to have difficulties finding a job were the most heavily subsidised. Based on the data used in this paper, the average subsidy paid by the government was, on average, 121 TND (or around 60 EUR) per month (2007 prices).

Originally, the SIVP was paid directly to employers. By 2004, however, it had turned into a salary of some sorts paid by the government directly to the graduate. The employer could, if he or she wished, top up this salary with a tax-free supplement. According to the data used in this study, the average value of this supplement was 238 TND per month in 2007 (or around 120 EUR). In other words: about two thirds of the graduate's wages were paid by the employer, and the government subsidised the other third. 
The subsidy was payable for a period of one year. During that time, the employer would also be exempt from social security contributions. The employer would remain exempt for another year if he or she recruited the graduate at the end of the subsidy period and (i) the graduate was the first subsidised graduate to be hired by the firm; or (ii) the graduate's degree was on the list of degrees considered to experience particular recruitment difficulties.

In sum, the SIVP represented a relatively large subsidy, substantially reducing the cost of hiring graduates for employers. The SIVP also reflected some of the good practice design features identified in the literature. For instance, if employers broke the contract, they were expected to reimburse the subsidies and pay the backlog of social security contributions. There were also requirements on the proportion of subsidised workers to be hired before any new ones could be taken on. Finally, the subsidy made an attempt at targeting those facing the greatest hiring difficulties by varying the value of the subsidy accordingly. It is clear, however, that the subsidy would likely have led to a very large deadweight loss: although there is a condition on the time spent unemployed (registered with ANETI), the subsidy is otherwise allocated on a first-come first-served basis. This means that many graduates would attract the subsidy, even though they were likely to have been hired in its absence. The programme also places no expectation/requirement on the beneficiaries to participate in other, complementary initiatives like training or job search - despite evidence that the combination of wage subsidies with such other programmes increases their effectiveness.

\section{Data and descriptive statistics}

The graduate tracer study (GTS) data used in this paper consists of a random and representative sample of 4,763 individuals who qualified in 2004 and were surveyed on two occasions: once in 2005 (around 1.5 years after graduation) and then again in 2007 (around 3.5 years after graduation). Sample attrition was relatively low: $89 \%$ responded to the first survey $(\mathrm{n}=4,250)$ and $79 \%(\mathrm{n}=3,751)$ to the second. The survey contains a range of sociodemographic and labour market information on the graduates as well as month-by-month calendar data on their main activity. ${ }^{12}$

Figure 1 below shows the main activity of graduates over the 44-month period covered by the calendar. As shown by the graph, the first six months of the calendar fall halfway through the academic year, so many students are still inactive/studying (month 1 of the calendar coincides with February 2004). The initial unemployment rate is very high (74\% in month nine, or about three months after graduation for most students in the survey), but falls steadily over time (to $35 \%$ in September 2007). The proportion on SIVP at any one point in time never exceeds 10\%, and reaches a peak around summer 2005 (or around one year after graduation for most students).

Only individuals who responded to both surveys $(n=3,751)$ are kept in the analysis. In addition, because we are interested in the outcomes of participants after they have left the SIVP programme, we need to drop observations that are still recorded as being on the programme in the last month of the calendar. 240 individuals are in this situation and are dropped from the analysis, leaving us with a final sample of 3,511 observations. Some individuals $(n=136)$ have more than one SIVP spell. For these graduates, we only consider the very first spell and ignore the later ones. For the remaining observations, participation in 


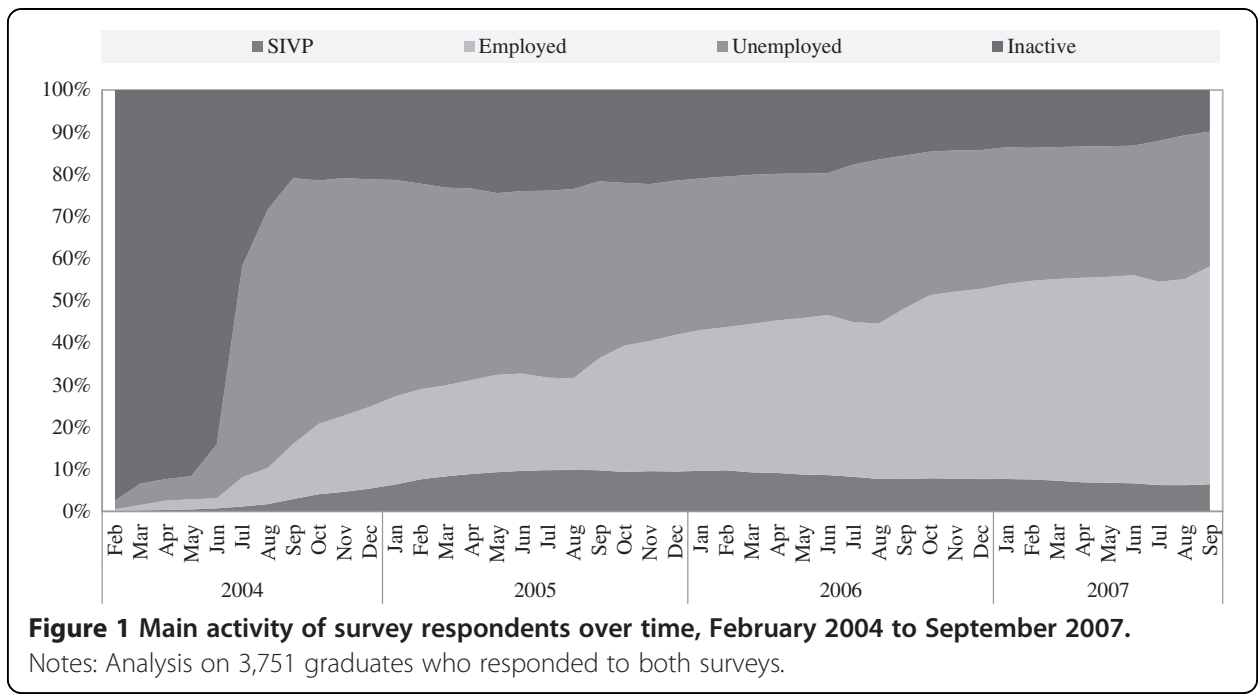

the programme is defined by whether the individual is observed as being in the programme for at least one month. This gives 834 treated individuals (23.8\%) participating in the programme for 11.5 months on average (the modal value being 12 months). Note also that participation in the programme may start at any point in time. On average, this is about one year after graduation. Survey weights are used throughout the analysis. ${ }^{13}$

Table 1 summarises the characteristics of the sample, broken down by treatment status. ${ }^{14}$ SIVP participants differ somewhat from non-participants. They are slightly younger, more likely to have been resident ${ }^{15}$ in the economically more prosperous North East, and had higher degree attainment. There are also differences in terms of the degrees and subjects studied. In general, SIVP participants are more likely to have studied lower (technician) level degrees and less likely to have studied Masters and "Other" degrees (which include architecture, medicine, etc...) Going back to the type of baccalaureate studied, SIVP participants appear significantly less likely to have studied Arts. An interesting final observation is that SIVP participants are much more likely to have done an internship during their studies, suggesting that participation in the SIVP is not random and that connections or personality matter (although, as will be shown below, internships do not reduce the chance of unemployment immediately after graduation).

Table 2 summarises the outcome variables used, again by treatment status. The following outcomes are considered: joblessness (unemployed or inactive); unemployment; whether or not the programme is successful in getting people jobs in the private sector (which, after all, is one of its main objectives); as well as the quality of that employment (whether or not the individual works for a contract; whether or not the contract is permanent/open-ended; as well as the individual's earnings).

The outcome variables are all measured at the time of the second survey (for the vast majority of individuals, this is November or December 2007). Because individuals graduate at different times, participate in the programme at different points in time, stay in the programme for different lengths of time, and are also interviewed at slightly different times, the time elapsed since graduation and participation in the programme will differ. For most of the main analysis presented in this paper, the time elapsed since participation in the programme is not taken into account. Later on, however, it will be verified whether the effects of the programme grow or fade with time. 
Table 1 Characteristics by treatment status

\begin{tabular}{|c|c|c|c|c|}
\hline & No SIVP & SIVP & Difference & P-value \\
\hline Gender: Female & $57.4 \%$ & $55.1 \%$ & $-2.4 \%$ & 0.237 \\
\hline Age (@ first interview, 1.6 months after graduation) & 26.6 & 26.3 & -0.3 & 0.009 \\
\hline Father's Education: Primary or less & $57.4 \%$ & $54.4 \%$ & $-3.1 \%$ & 0.126 \\
\hline Father's Education: Secondary & $30.2 \%$ & $33.1 \%$ & $2.9 \%$ & 0.125 \\
\hline Father's Education: Tertiary & $12.3 \%$ & $12.5 \%$ & $0.2 \%$ & 0.879 \\
\hline Internship & $61.4 \%$ & $77.7 \%$ & $16.3 \%$ & 0.000 \\
\hline Major: Technician - Business, law and language & $9.4 \%$ & $13.3 \%$ & $3.9 \%$ & 0.001 \\
\hline Major: Technician - STEM & $14.1 \%$ & $21.5 \%$ & $7.4 \%$ & 0.000 \\
\hline Major: Technician - Health and social services & $2.8 \%$ & $6.3 \%$ & $3.6 \%$ & 0.000 \\
\hline Major: Technician - Other & $4.0 \%$ & $2.7 \%$ & $-1.3 \%$ & 0.096 \\
\hline Major: Masters - Business, law and languages & $40.7 \%$ & $38.8 \%$ & $-1.8 \%$ & 0.363 \\
\hline Major: Masters - STEM & $14.6 \%$ & $6.3 \%$ & $-8.3 \%$ & 0.000 \\
\hline Major: Masters - Other & $4.7 \%$ & $2.2 \%$ & $-2.6 \%$ & 0.001 \\
\hline Major: Engineer & $3.7 \%$ & $5.4 \%$ & $1.7 \%$ & 0.031 \\
\hline Major: Other degrees & $6.0 \%$ & $3.3 \%$ & $-2.7 \%$ & 0.003 \\
\hline Degree Attainment: Pass & $62.9 \%$ & $56.1 \%$ & $-6.7 \%$ & 0.001 \\
\hline Degree Attainment: Satisfactory & $22.8 \%$ & $25.3 \%$ & $2.6 \%$ & 0.133 \\
\hline Degree Attainment: Good & $10.5 \%$ & $14.2 \%$ & $3.7 \%$ & 0.004 \\
\hline Degree Attainment: Very Good & $3.9 \%$ & $4.4 \%$ & $0.5 \%$ & 0.539 \\
\hline Bac: Mathematics & $21.8 \%$ & $22.1 \%$ & $0.4 \%$ & 0.819 \\
\hline Bac: Technical & $10.4 \%$ & $13.9 \%$ & $3.5 \%$ & 0.006 \\
\hline Bac: Science & $23.2 \%$ & $28.1 \%$ & $4.9 \%$ & 0.005 \\
\hline Bac: Economics and Management & $13.4 \%$ & $18.0 \%$ & $4.6 \%$ & 0.001 \\
\hline Bac: Arts & $31.3 \%$ & $17.9 \%$ & $-13.4 \%$ & 0.000 \\
\hline Region: North East & $40.5 \%$ & $54.1 \%$ & $13.6 \%$ & 0.000 \\
\hline Region: North West & $8.7 \%$ & $5.0 \%$ & $-3.7 \%$ & 0.001 \\
\hline Region: Centre East & $25.5 \%$ & $23.9 \%$ & $-1.7 \%$ & 0.339 \\
\hline Region: Centre West & $9.5 \%$ & $5.0 \%$ & $-4.5 \%$ & 0.000 \\
\hline Region: South East & $8.9 \%$ & $5.1 \%$ & $-3.8 \%$ & 0.001 \\
\hline Region: South West & $6.8 \%$ & $6.9 \%$ & $0.1 \%$ & 0.957 \\
\hline
\end{tabular}

Table 2 Labour market outcomes, by treatment status

\begin{tabular}{llllll}
\hline & No SIVP & SIVP & Difference & P-value & N \\
\hline Jobless & 0.322 & 0.253 & -0.069 & 0.000 & 3511 \\
Unemployed $^{\mathrm{a}}$ & 0.360 & 0.270 & -0.090 & 0.000 & 3198 \\
Private firm $^{\mathrm{a}}$ & 0.217 & 0.505 & 0.288 & 0.000 & 3198 \\
Contract $^{\mathrm{b}}$ & 0.821 & 0.852 & 0.031 & 0.094 & 2112 \\
Permanent contract $^{\mathrm{c}}$ & 0.619 & 0.377 & -0.243 & 0.000 & 1752 \\
Earnings (TND) $^{\mathrm{b}}$ & 582 & 530 & -52 & 0.007 & 1955 \\
\hline
\end{tabular}

${ }^{a}$ Conditional on being active ${ }^{b}$ Conditional on being employed ${ }^{c}$ Conditional on having a contract. Notes: 157 observations have missing earnings information. These are dropped from the earnings analysis. 
As Table 2 shows, SIVP beneficiaries are less likely to be jobless ( -7 percentage points) and unemployed ( -9 percentage points). Conditional on being active, SIVP beneficiaries are considerably more likely to find jobs in the private sector ( +29 percentage points), suggesting that private firms hire a large portion of ex-SIVP beneficiaries. There appears to be no effect of the programme on the likelihood of working for a contract but, conditional on working for a contract, SIVP beneficiaries are considerably less likely to have a permanent one ( -24 percentage points). They also appear to earn less (-52 TND, or nearly $-9 \%)$. This suggests that the work found by SIVP participants is more precarious and less well remunerated than that of non-participants.

\section{Unemployment and participation in the SIVP programme}

The descriptive statistics presented in the previous section suggest that participation in the SIVP programme is not random. In this section we use multivariate analysis to try and unpack this story a little more. In particular, we start by looking at the determinants of unemployment and compare those to: (i) the determinants of participation in the SIVP programme; and (ii) the factors associated with earlier take-up of the programme (i.e. how soon after graduation individuals find a subsidised placement). Table 3 below presents the results and the rest of this section describes the findings in some detail.

To summarise the discussion up front, we find that the characteristics of individuals most strongly associated with unemployment in the first three months after graduation are not necessarily those associated with participation in the programme. In fact, the data suggest no relationship between the risk of unemployment in the first three months after graduation and participation in the programme. There is some evidence also that the risk of unemployment is negatively associated with the timing of SIVP participation - i.e. those individuals most likely to be unemployed for the first three months after graduation are those who tend to have to wait the longest before they participate in the programme. Overall, therefore, these findings suggest that the SIVP programme is not effectively targeting those who need it most.

Column (i) of Table 3 shows the results of an OLS regression ${ }^{16}$ where the dependent variable is a dichotomous indicator equal one if the individual spent the first three months after graduation unemployed, and zero otherwise. From Section 'The SIVP programme', we know that individuals were not eligible to participate in the programme until they had been registered with the public employment service for at least three months. A threemonth unemployment spell immediately after graduation can thus be taken as a reasonably good indicator (exogenous to participation in the programme) of the extent of a graduate's labour market distress. The results show that risk of unemployment immediately after graduation is highest for: older graduates, those whose fathers only had primary education, those with technician-level degrees, and those from some of the poorest regions in Tunisia (the South East and the South West).

Column (ii) then estimates the characteristics associated with SIVP take-up. Only three of the characteristics which were associated with a higher/lower risk of unemployment also increase/decrease the chances of participating in the programme: having completed a technician-level degree in "Business, Law and Languages" (higher chance of participation); having completed an "Other" degree (lower chance); and coming from the Centre East (lower chance). Apart from these, none of the other characteristics associated with higher/lower unemployment are also associated with an increased/decreased likelihood of 
Table 3 Labour market outcomes, by treatment status

\begin{tabular}{|c|c|c|c|c|c|}
\hline & $\begin{array}{l}\text { Unemployed } \\
\text { first } 3 \text { months }\end{array}$ & $\begin{array}{l}\text { Participation } \\
\text { in the SIVP } \\
\text { programme }\end{array}$ & & $\begin{array}{l}\text { Timing } \\
\text { SIVP ta }\end{array}$ & \\
\hline & (i) & (ii) & (iii) & $(v)$ & (vi) \\
\hline \multirow[t]{2}{*}{ Spent first three months unemployed } & & & -0.02 & & $9.96^{* * *}$ \\
\hline & & & $(0.01)$ & & $(0.56)$ \\
\hline \multirow[t]{2}{*}{ Gender: Female } & 0.02 & -0.01 & & $1.48^{*}$ & \\
\hline & $(0.02)$ & $(0.02)$ & & $(0.63)$ & \\
\hline \multirow[t]{2}{*}{ Age ( 1.6 months after graduation) } & $0.01^{* *}$ & 0.00 & & -0.12 & \\
\hline & $(0.00)$ & $(0.00)$ & & $(0.14)$ & \\
\hline \multirow[t]{2}{*}{ Father's Education: Secondary } & $-0.05^{*}$ & 0.00 & & 0.16 & \\
\hline & $(0.02)$ & $(0.02)$ & & $(0.66)$ & \\
\hline \multirow[t]{2}{*}{ Father's Education: Tertiary } & $-0.12^{* * *}$ & -0.02 & & -0.65 & \\
\hline & $(0.03)$ & $(0.02)$ & & $(0.92)$ & \\
\hline \multirow[t]{2}{*}{ Internship } & -0.02 & $0.08^{* * *}$ & & -0.06 & \\
\hline & $(0.02)$ & $(0.02)$ & & $(0.77)$ & \\
\hline \multirow[t]{2}{*}{ Major: Technician - Business, law and language } & $0.09^{* *}$ & $0.06^{*}$ & & $-2.85^{* *}$ & \\
\hline & $(0.03)$ & $(0.03)$ & & $(1.03)$ & \\
\hline \multirow[t]{2}{*}{ Major: Technician - STEM } & $0.11^{* * *}$ & 0.02 & & -0.77 & \\
\hline & $(0.03)$ & $(0.03)$ & & $(1.07)$ & \\
\hline \multirow[t]{2}{*}{ Major: Technician - Health and social services } & -0.05 & $0.12^{* *}$ & & $-4.18^{* *}$ & \\
\hline & $(0.05)$ & $(0.04)$ & & $(1.32)$ & \\
\hline \multirow[t]{2}{*}{ Major: Technician - Other } & 0.05 & -0.06 & & -2.68 & \\
\hline & $(0.05)$ & $(0.04)$ & & $(1.85)$ & \\
\hline \multirow[t]{2}{*}{ Major: Masters - STEM } & 0.00 & $-0.14^{* * *}$ & & 0.48 & \\
\hline & $(0.03)$ & $(0.03)$ & & $(1.29)$ & \\
\hline \multirow[t]{2}{*}{ Major: Masters - Other } & 0.02 & $-0.08^{*}$ & & -1.01 & \\
\hline & $(0.04)$ & $(0.04)$ & & $(2.06)$ & \\
\hline \multirow[t]{2}{*}{ Major: Engineer } & -0.08 & 0.00 & & $-3.17^{*}$ & \\
\hline & $(0.05)$ & $(0.04)$ & & $(1.47)$ & \\
\hline \multirow[t]{2}{*}{ Major: Other degrees } & $-0.28^{* * *}$ & $-0.10^{* *}$ & & -0.94 & \\
\hline & $(0.04)$ & $(0.03)$ & & $(1.80)$ & \\
\hline \multirow[t]{2}{*}{ Degree Attainment: Satisfactory } & $-0.07^{* *}$ & 0.00 & & 0.03 & \\
\hline & $(0.02)$ & $(0.02)$ & & $(0.76)$ & \\
\hline \multirow[t]{2}{*}{ Degree Attainment: Good } & -0.04 & 0.00 & & 0.66 & \\
\hline & $(0.03)$ & $(0.02)$ & & $(0.97)$ & \\
\hline \multirow[t]{2}{*}{ Degree Attainment: Very Good } & -0.04 & -0.05 & & 0.44 & \\
\hline & $(0.05)$ & $(0.04)$ & & $(1.52)$ & \\
\hline \multirow[t]{2}{*}{ Bac: Mathematics } & $-0.06^{*}$ & 0.00 & & -0.23 & \\
\hline & $(0.03)$ & $(0.03)$ & & $(1.00)$ & \\
\hline \multirow[t]{2}{*}{ Bac: Technical } & -0.02 & 0.03 & & 0.98 & \\
\hline & $(0.04)$ & $(0.03)$ & & $(1.27)$ & \\
\hline \multirow[t]{2}{*}{ Bac: Science } & 0.00 & 0.01 & & 1.64 & \\
\hline & $(0.03)$ & $(0.02)$ & & $(0.93)$ & \\
\hline \multirow[t]{2}{*}{ Bac: Arts } & -0.04 & $-0.08^{* * *}$ & & 1.63 & \\
\hline & $(0.03)$ & $(0.02)$ & & $(1.01)$ & \\
\hline
\end{tabular}


Table 3 Labour market outcomes, by treatment status (Continued)

\begin{tabular}{llll}
\hline Region: North West & 0.00 & $-0.12^{* * *}$ & 1.02 \\
Region: Centre East & $(0.03)$ & $(0.03)$ & $(1.35)$ \\
& $-0.08^{* * *}$ & $-0.06^{* *}$ & $-1.69^{*}$ \\
Region: Centre West & $(0.02)$ & $(0.02)$ & $(0.71)$ \\
& 0.04 & $-0.12^{* * *}$ & $4.59^{* * *}$ \\
Region: South East & $(0.03)$ & $(0.03)$ & $(1.34)$ \\
& $0.10^{* *}$ & $-0.14^{* * *}$ & 1.33 \\
Region: South West & $(0.03)$ & $(0.03)$ & $(1.35)$ \\
& $0.12^{* * *}$ & -0.04 & 0.45 \\
$\mathrm{n}$ & $(0.03)$ & $(0.03)$ & $(1.20)$ \\
\hline * $\mathrm{p}<0.05 ;{ }^{* *} \mathrm{p}<0.01$; ** $\mathrm{p}<0.001$. & 3511 & 3511 & 834 \\
Omitted categories: Gender: Male; Father's Education: Primary; Major: Masters - Business, law and languages; Degree \\
Attainment: Pass; Bac: Economics and Management; Region: North East.
\end{tabular}

participating in the programme. In one case, the relationship is even negative: individuals coming from the poor South East are 10 percentage points more likely to spend the first three months after graduation unemployed (than individuals living in Greater Tunis), but they are 14 percentage points less likely to benefit from the programme. That unemployment in the first three months after graduation is unrelated to participation in the programme is further confirmed in column (iii) of Table 3, which shows the result of a simple regression of participation on unemployment: the coefficient is negative and small, as well as statistically insignificant.

Finally, in column (iv), we look at the timing of SIVP take-up (i.e. how soon after graduation individuals enrol in the programme), and the characteristics associated with that. The dependent variable is measured in months, and the regression is run on the sub-sample of SIVP beneficiaries $(n=834)$. We find that only one of the characteristics associated with a higher/lower chance of unemployment also shortens/lengthens the time between graduation and SIVP take-up (having a degree in "Business, Law and Languages"). Again, one characteristic appears to have the opposite effect (i.e. a lower risk of unemployment, but a shorter time between graduation and participation in the programme), and that is coming from the Centre East (one of Tunisia's more affluent and industrialised areas). Apart from that, we find few parallels between the results in columns (i) and (iv). Column (v) also presents a simple regression of the timing of SIVP participation on the probability of spending the first three months after graduation unemployed, and the relationship is positive (i.e. those individuals who spend the first three months after graduation unemployed wait nearly 10 months longer on average before they participate in the programme). All this suggests, once again, that the programme appears to be poorly targeted.

\section{SIVP participation and employment outcomes}

We now turn to a more detailed analysis of the impact of SIVP participation on postprogramme labour market outcomes. As mentioned previously, the time elapsed since leaving the programme will differ for each participant. In a later section, we will explore whether the effects of the programme fade or grow with time. For now, we ignore this aspect in the analysis. 
The data are non-experimental, and there is no natural experiment, instrument or discontinuity in treatment to exploit. We will therefore need to assume that selection into the programme occurs on the basis of observable characteristics only. For reasons already cited, this is unlikely to be a realistic assumption. In other contexts, a lack of waterproof methodology might lead researchers to abandon their study. However, given the lack of research available on active labour market programmes in the MENA region, assessing the SIVP programme as best as one can with the methodologies available would seem an important contribution to the literature. It is hoped, however, that future labour market programmes in Tunisia will be set up with more rigorous impact evaluations in mind. ${ }^{17}$

In what follows, two techniques are used: Ordinary Least Squares (OLS) regressions and Propensity Score Matching (PSM). Both techniques assume that selection into the programme is based on observable characteristics only. ${ }^{18}$ The advantage of PSM over OLS is that PSM allows for non-linear relationships without the need to know how to model them. It is assumed that readers are sufficiently familiar with PSM as a technique and so it will not be discussed in further detail here. For good introductory overviews of the method, the reader is referred to Heinrich et al. (2010) or Caliendo and Kopeinig (2008). The original treatment of the technique can be found in Rosenbaum and Rubin (1983). ${ }^{19}$

Kernel matching is used, imposing common support. ${ }^{20}$ Other matching estimators have been experimented with (Kernel with trimming, one-to-one matching, nearest neighbour, radius caliper, and local linear) - but the results did not vary substantially with these different estimators. In all regressions (including the estimation of the propensity score), the explanatory variables used are more detailed than the ones reported so far. So, for example, governorate is used instead of region, a more detailed breakdown of major is used, as well degree attainment measured in point scores (instead of categories). The institution from which the degree was obtained is also included, as is a dummy variable indicating whether or not the individual had been registered with ANETI (the public employment service).

The main results of the effect of SIVP on subsequent labour market outcomes are presented in Table 4 below. The table includes the coefficients on the SIVP variables, the standard errors, the number of observations, as well as the R. ${ }^{2}$ In the case of the PSM models, the table also reports the number of observations on support, the mean standardised bias after matching ${ }^{21}$, as well as the results of an F-test of the joint significance of all regressors in a probit estimation of the propensity score (or conditional treatment probability). If the matching is done correctly, the test should be rejected (i.e. the variables should not predict treatment probability).

The results confirm a few findings from the descriptive analysis: those who benefited from a SIVP subsidy appear less likely to be jobless ( -8.0 percentage points), less likely to be unemployed ( -9.8 percentage points); and they are still significantly more likely to find a job in the private sector ( +21.5 percentage points) - although the effect has been reduced. The effect on the likelihood of having a contract is now positive $(+5.6$ percentage points) and significant, but ex-beneficiaries remain significantly less likely ( -15.6 percentage points) to have an open-ended contract. Finally, the effect on earnings becomes insignificant in the multivariate analysis. Some preliminary examination suggests that about half the effect on contract type can be explained by the sector of 
Table 4 The effect of SIVP participation on labour market outcomes

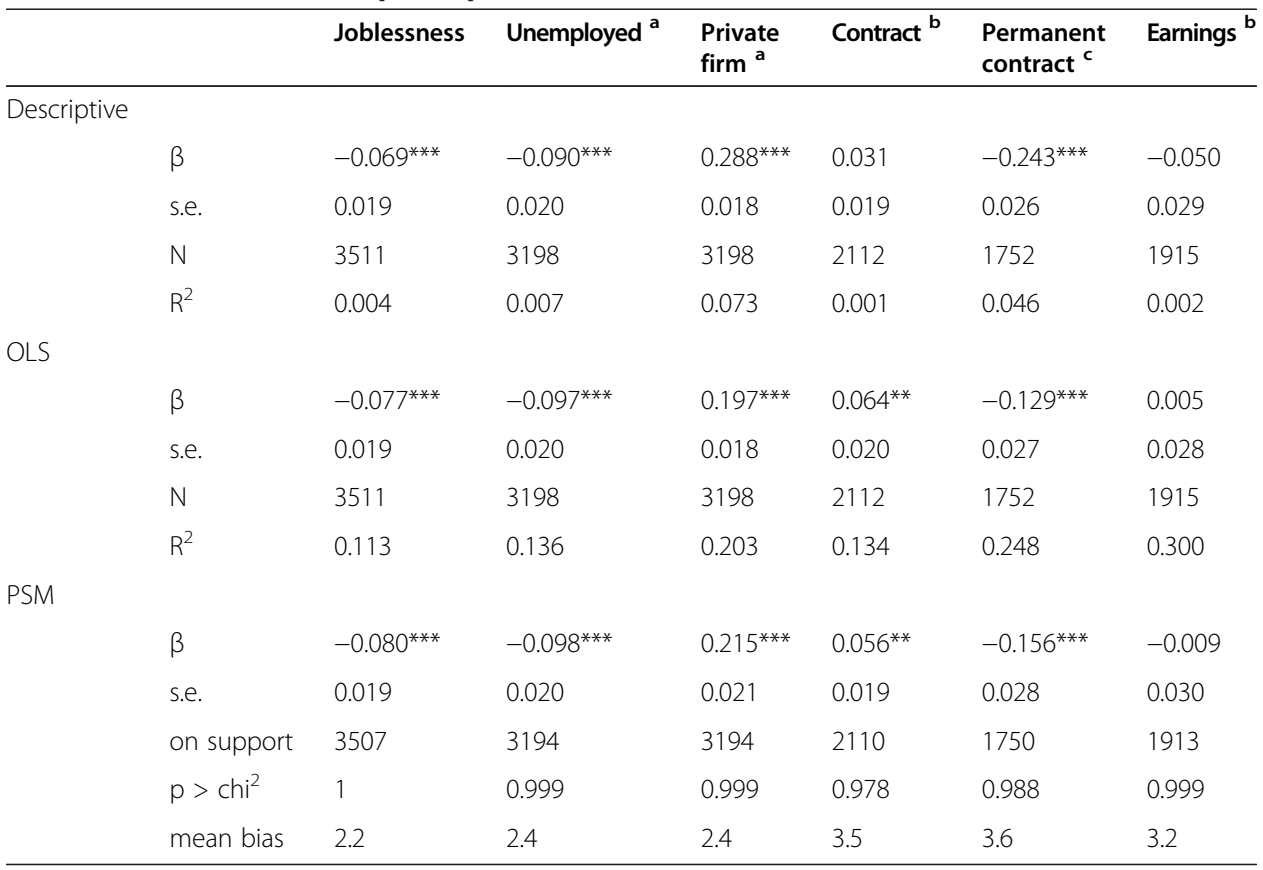

${ }^{*} p<0.05 ;{ }^{* *} p<0.01 ;{ }^{* *} p<0.001$.

a Conditional on being active ${ }^{\mathrm{b}}$ Conditional on being employed ${ }^{\mathrm{C}}$ Conditional on having a contract.

Notes: earnings regressions are in semi-log form.

employment. In particular, it turns out that nearly half of those who did not benefit from a SIVP found work as a teacher in the public sector, most of whom are on open-ended contracts.

In Table 5 below, the PSM analysis of Table 7 is broken down by sub-group to explore heterogeneity in treatment effects. Only unemployment is kept as a dependent variable. Males are compared to females, and those residing in Greater Tunis (North East) to those residing outside (rest of the country). In addition, we compare those who had studied a degree with employment difficulties ${ }^{22}$ to those who had not (remember from Section 'The SIVP programme' that the subsidies were generally larger for those who had studied the former type of degrees, so we would expect a greater employment effect for them). Finally, we also split the analysis by whether or not the individual spent the first three months immediately after graduation as unemployed. Note that each time the propensity score is calculated separately for every sub-group (i.e. separately for males and females, etc...)

Although none of the differences are statistically significant, it is interesting to note that the employment impacts of the SIVP appear largest for women, for those residing outside Tunis and its surroundings, and for those spending the first three months after graduation unemployed. So a greater targeting of the SIVP on individuals who have higher unemployment probabilities might be expected to increase the effectiveness of the programme. Individuals who studied degrees with employment difficulties appear to be more likely to be unemployed post-SIVP - however this is not necessarily an indication that the additional subsidies provided to employers for hiring such graduates have not been successful. Indeed, in the absence of such additional incentives the difference in employment outcomes might have been even greater.

Finally, a couple of robustness checks are done. First, the PSM analysis of Table 4 is re-run by strata. In essence, four different groups are created: women in the 
Table 5 The effect of SIVP participation on unemployment, by sub-group

\begin{tabular}{llllllllll}
\hline & Gender & & Region & & \multicolumn{2}{l}{$\begin{array}{l}\text { Subject with } \\
\text { insertion } \\
\text { difficulties }\end{array}$} & $\begin{array}{l}\text { Unemployed first } \\
\text { 3 months after } \\
\text { graduation }\end{array}$ \\
\hline & Male & Female & $\begin{array}{l}\text { North } \\
\text { East }\end{array}$ & $\begin{array}{l}\text { Rest of } \\
\text { Country }\end{array}$ & Yes & No & Yes & No \\
$\beta$ & $-0.072^{* *}$ & $-0.118^{* * *}$ & $-0.091^{* *}$ & $-0.113^{* * *}$ & -0.081 & $-0.104^{* * *}$ & $-0.120^{* * *}$ & $-0.071^{*}$ \\
s.e. & 0.027 & 0.029 & 0.028 & 0.028 & 0.046 & 0.023 & 0.029 & 0.029 \\
on support & 1439 & 1753 & 1242 & 1952 & 804 & 2390 & 1722 & 1473 \\
$p>$ chi2 & 1.000 & 1.000 & 1.000 & 0.997 & 0.989 & 1.000 & 1.000 & 1.000 \\
mean bias & 3.1 & 3.1 & 2.8 & 2.9 & 5.1 & 2.3 & 2.7 & 2.9 \\
$\begin{array}{l}\text { Test of equality of } \\
\text { coefficients }\end{array}$ & & 1.14 & & 0.54 & & -0.45 & & 1.20 \\
\hline
\end{tabular}

${ }^{*} p<0.05 ; * * p<0.01 ; * * *<0.001$

Notes: All results reported based on Kernel PSM with common support imposed. Conditional on being active.

Test of equality of coefficients using the formula: $Z=\frac{b_{1}-b_{2}}{\sqrt{s . e . b_{1}^{2}-s . e . b_{2}^{2}}}$

Table 6 The effect of SIVP participation on labour market outcomes over time

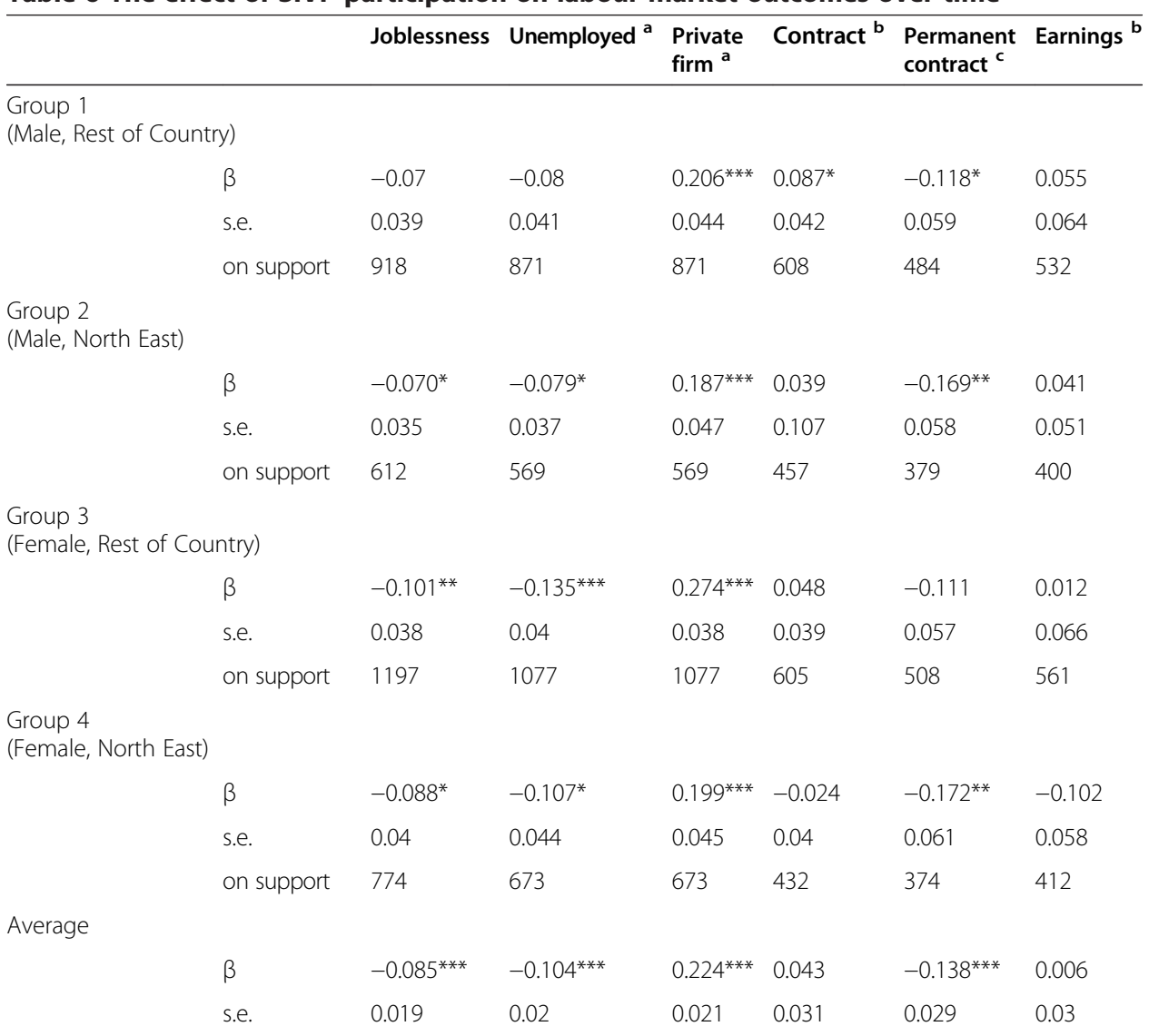

${ }^{*} p<0.05 ; *$ * $p<0.01 ;{ }^{* * *} p<0.001$.

${ }^{a}$ Conditional on being active ${ }^{b}$ Conditional on being employed ${ }^{c}$ Conditional on having a contract.

Notes: earnings regressions are in semi-log form.

Average $\beta$ calculated using the following formula: $\bar{\beta}=\frac{\sum_{i=1}^{4}}{\sum_{i=1}^{4} \beta_{i}}$, where $i$ indicates the group number.

Average standard error calculated using the following formula: $\bar{\sigma}=\sqrt{\frac{\sum_{i=0}^{4}, n_{0}^{2} i n_{i}}{\sum_{i=1}^{i} n_{i}}}$, where $i$ indicates the group number. 
Table 7 The effect of SIVP participation on labour market outcomes over time

\begin{tabular}{|c|c|c|c|c|c|c|}
\hline & Joblessness & Unemployed $^{\mathrm{a}}$ & $\begin{array}{l}\text { Private } \\
\text { firm }^{a}\end{array}$ & Contract $^{b}$ & $\begin{array}{l}\text { Permanent } \\
\text { contract }^{c}\end{array}$ & Earnings ${ }^{a}$ \\
\hline SIVP 1-18 months ago & $-0.054^{*}$ & $-0.080^{* *}$ & $0.214^{* * *}$ & $0.060^{*}$ & $-0.203^{* * *}$ & -0.036 \\
\hline s.e. & 0.025 & 0.026 & 0.024 & 0.025 & 0.034 & 0.035 \\
\hline SIVP 19+ months ago & $-0.101^{* * *}$ & $-0.116^{* * *}$ & $0.178^{* * *}$ & $0.068^{* *}$ & -0.055 & 0.049 \\
\hline s.e. & 0.025 & 0.026 & 0.024 & 0.025 & 0.034 & 0.036 \\
\hline Test of equality & 2.20 & 1.18 & 1.37 & 0.06 & 12.29 & 3.74 \\
\hline
\end{tabular}

North East, men in the North East, women in the rest of the country, and men in the rest of the country. The propensity scores are calculated separately for each of these groups and the matching is done separately as well. A weighted average of the results is then estimated. The results are presented in Table 6 lead to essentially the same conclusions as those reached based on Table 4 .

So far, we have assumed that labour market outcomes are the same, regardless of whether the individual left a subsidised placement just one month ago, or whether she did so over a year ago. In a second robustness check, we test whether the effects of SIVP grow or fade over time. To do this, we replace the SIVP variable in the OLS regressions of Table 4 by two new variables: one indicating whether the individual completed a SIVP subsidy less than 1.5 years ago and one indicating whether the individual completed one over 1.5 years ago. The coefficients of these two variables are reported in Table 7 below, as well as the results from a test of their equality. The SIVP reduces joblessness and unemployment both in the short- and long-run. The impact appears to increase with time, however we cannot reject the null hypothesis that both coefficients are equal. Similarly with the impact on a private sector job: in the long-run, SIVP participants appears to be moving into the public sector, although again the coefficients are not statistically different from one another. We do observe a statistically significant impact of time since SIVP on the likelihood of working for a permanent contract. SIVP beneficiaries who left the programme more than 18months ago are no less likely than non-beneficiaries to be on a temporary contract. Finally, we also observe a difference in earnings over time. Although neither estimate is statistically different from those of non-beneficiaries, they are statistically different from one another - implying that earnings increase with time since leaving the programme. ${ }^{23}$

\section{Discussion and conclusion}

The purpose of this paper was to add to a very scarce literature on the effectiveness of active labour market policies in MENA countries. In particular, the paper looked at the SIVP - an employment subsidy in Tunisia aimed at increasing graduate employment. Although the findings in this paper cannot necessarily be interpreted as causal, it is hoped that the analysis at least contributes to our understanding of how employment subsidies in North Africa are being implemented, with a view to improving such programmes in the future.

In the best case scenario (assuming our estimates are causal and there is no deadweight loss or substitution effect), this paper has estimated that the SIVP decreased the 
joblessness rate of university graduates by 8 percentage points. Given that: (i) there were around 38,000 graduates in $2004^{24}$; (ii) around one in four of these benefited from a SIVP (or 9,500 individuals); (iii) the joblessness rate of non-beneficiaries was around $60 \%$; then the SIVP would have led to an additional 760 individuals in work. Further assuming that the programme cost approximately TND 1,440 per participant ${ }^{25}$ (or a total of TND 1,140 × 9,500 = TND 13.68m), this implies a cost per job created of around TND 18,000 (or EUR 9,000). This compares to an estimated cost per job created by hiring credits in the United States of between USD 9,100 and USD 75,000 (Neumark 2013). Both the employment effect estimated and the cost-effectiveness of the programme thus appear in line with what has been found in the international literature.

However, one key conclusion of this paper is that the SIVP, the way it was designed back in 2004, would probably have had a very large deadweight loss. This is primarily because individuals self-selected into the programme and subsidies were allocated on a first-come first-served basis - meaning that the most employable graduates would probably have been more likely to benefit from the programme. This is indeed one of the conclusions reached by the descriptive analysis. It is also consistent with a World Bank (2012) finding that around 75\% of firms who benefited from the SIVP (and other programmes) said they would have recruited even in the absence of the subsidy. Another best-practice design feature emerging from the international literature and absent from the SIVP is the combination of the subsidy with other services such as training, counselling and/or job search assistance.

The SIVP as it was analysed in this paper no longer exists. It was changed to some extent in 2009 and it will soon be phased out to make place for the Chèque d'Appui à l'Emploi - or the Employment Support Cheque. However, it is clear that this new programme is a direct descendant of the SIVP and, indeed, still bears many similarities to it. ${ }^{26}$ In particular, the cheque's targeting is no better than the SIVP's, nor does it make training or any other employability programmes a compulsory requirement for receiving the subsidy (despite the fact that experience with subsidies in other countries has shown that they tend to be more effective if they are combined with other such interventions). It is a shame, therefore, that employment subsidies in Tunisia will, in all likelihood, continue to be provided in a wasteful manner, with large deadweight losses. This is not to say, of course, that deadweight losses are entirely avoidable - they are an inherent attribute of such programmes - just that deadweight losses are a question of degree, and can be reduced substantially if good practice in wage subsidy design is abided by.

A final observation is that, in Tunisia, the SIVP is not used as a countercyclical tool, but rather as an instrument to try and tackle (or at least alleviate) a persistent and structural unemployment problem. It has been in place, in one form or another, continuously since 1987, and benefits a very large portion of graduates (nearly half). This raises yet another question about its effectiveness: while the literature has shown that temporary wage subsidies to tackle cyclical unemployment can be highly effective, and while it is likely that the SIVP alleviates at least some of the problem, it is not (and cannot be seen) as a long-term and durable solution to the unemployment problem in Tunisia. For that, employment-friendly growth will be required, as well as more structural reforms of the labour market. 


\section{Endnotes}

${ }^{1} 18.9 \%$ in Egypt, $19.4 \%$ in Morocco, and $21.4 \%$ in Algeria.

${ }^{2}$ It was later denied, however, including by his own family members, that he had a university degree. Irrespective of the truth regarding Mohamed Bouazizi's qualifications, it is widely agreed that the level of unemployment among university graduates in Tunisia contributed to the rise of social discontent in the run-up to the revolution.

${ }^{3}$ The graduate unemployment rate in Tunisia is considerably higher than that for other levels of education. In 2010, unemployment affected $15.7 \%$ of those with secondary qualifications, $11.7 \%$ of those with primary qualifications, and just $6.7 \%$ of those with no qualifications.

${ }^{4}$ The terms wage/employment subsidies and hiring credits are often used interchangeably in the literature. In this paper, the term employment subsidy will be used throughout.

${ }^{5}$ This does not include administration costs.

${ }^{6}$ In a similar vein, Neumark (2013) compares the cost effectiveness of various policies in the United States to incentivise job creation in the case of severe recessions, and concludes that hiring credits are more than twice as effective per dollar spent than general fiscal stimulus.

${ }^{7}$ The term deadweight loss will be used in this paper following, for example, Martin (2000), Betcherman et al. (2004), amongst others. Elsewhere in the literature, the terms "windfall" or "wastage" are used. In the context of wage subsidies, these are taken to mean the same thing.

${ }^{8}$ The most important ones are: Law n ${ }^{\circ} 81-75$ dated 9 August 1981 pertaining to the promotion of youth employment; Decree n ${ }^{\circ} 87-1190$ dated 26 August 1987 creating the SIVP programme; Decree $\mathrm{n}^{\circ}$ 93-17 dated 22 February 1993, modifying and supplementing Law $\mathrm{n}^{\circ}$ 81-75; Decree $\mathrm{n}^{\circ}$ 93-1049 dated 3 May 1993 pertaining to the promotion of youth employment; and the Bylaw dated 15 June 1995, fixing the modalities of application of Decree 93-1049. In 2012, new legislation was introduced which will turn the SIVP into a Chèque d'Appui à l'Emploi - the employment support cheque. The essence of this programme is very similar to the SIVP, and will be discussed in the conclusion of this paper.

${ }^{9}$ This list was meant to have been established on a yearly basis, but the only trace of such a list is the bylaw cited. Conversations with officials suggest that this list was barely used.

${ }^{10}$ Note that a small proportion of SIVP internships occurs in public enterprises. At the time of the second survey, $4 \%$ of subsidised graduates worked in public enterprises. From the calendar, it is impossible to distinguish the firm type (public or private) and so the main analysis in this paper does not differentiate between these.

${ }^{11}$ Subsidies are also available for young people with lower levels of qualifications. Overall, firms with more than 10 workers could have up to $40 \%$ of their staff members subsidised.

${ }^{12}$ In the case of school-to-work transitions, there is only a limited amount that can be done with the panel element of the data as there is no clear pre-treatment outcome. However, because individuals vary in their timing of graduation, SIVP take-up and interviews, as well as in the duration of their SIVP participation, the calendar information is useful for calculating more exact times of graduation, SIVP participation, and exit from the programme. These, in turn, are then used in the paper to calculate short- and long-term effects of the programme. 
${ }^{13}$ Including for the calculation of the propensity scores, although the effect of treatment on the treated is not estimated using weights.

${ }^{14}$ The quality of the data is generally very high. Occasionally, some values are missing. Age is missing for 14 observations; father's education for 1 observation; baccalaureate type for 2 observations; internship for 25 observations; and degree attainment for 5 observations. These observations have been left out of Table 1 . In the analysis that follows, missing values have been set to zero, and a dummy variable indicating missing values was included in the analysis.

${ }^{15}$ Residence is measured at the time of the first survey.

${ }^{16} \mathrm{~A}$ Linear Probability Model is used instead of a probit model for ease of interpretation. The results and conclusions reached are insensitive, however, to this choice of model.

${ }^{17}$ Again, there are signs that the situation is improving. Apart from the paper by Premand et al. (2012) already cited (which uses a randomised controlled trial), the legislation for the soon-to-be-introduced Chèque d'Appui à l'Emploi emphasises the need for independent evaluation and sets up the necessary conditions for this.

${ }^{18}$ In the case of PSM, given that selection into the programme probably occurs on unobservables as well, this means that the Conditional Independence Assumption (CIA) is unlikely to hold.

${ }^{19}$ The programme PSMATCH2 is used (Leuven and Sianesi 2003).

${ }^{20}$ In the tables below, the number of observations on support will be reported. In all cases, the number of observations lost due to lack of support is miniscule. I have also tried trimming the data instead, but this does not alter the results obtained in this paper.

${ }^{21} \mathrm{~A}$ bias reduction to between $3 \%$ and $5 \%$ is generally regarded as successful.

${ }^{22}$ There is no one-to-one mapping of the degrees considered to face insertion difficulties and the values of the degree variables in the GTS (partly because the value labels for the most detailed degree variable were not available). The following are considered degrees with insertion difficulties: Technician in Law and Applied Languages; Technician in Chemistry, Biology and Water Treatment; Technician in Agriculture and Food Industry; Masters in Arabic; Masters in Engineering Technologies; Masters in Mathematics, Physics and Chemistry; Masters in Law; Agricultural and Food Engineering; Technologies Engineering; and Electrical Engineering.

${ }^{23}$ Unless, of course, this difference in earnings simply reflects the fact that better graduates obtain a subsidy first.

${ }^{24}$ Source: Ministère de l'Emploi et de l'Insertion Professionnelle des Jeunes and World Bank (2009).

${ }^{25}$ Approximately TND 120 (average government subsidy according to the survey) time 12 months (average time spent on the subsidy).

${ }^{26}$ See Decree $n^{\circ} 2012-2369$ dated 16 October 2012 fixing the programmes of the national employment fund, their conditions and the benefit modalities. The only significant difference with the SIVP is that the Chèque normalises the contractual relationship between the graduate and the firm into a standard employment contract (permanent or temporary), which entitles the beneficiary to build up pension rights and other social advantages. 


\section{Acknowledgements}

I am very grateful to the Observatoire National de l'Emploi et des Qualifications for granting me access to the data as well as for clarifications about the SIVP programme itself. I would also like to thank the research department at the African Development Bank where a good deal of this paper was drafted. Tahar Abdessalam, Loubna Bourkane, Ousman Gajigo and Amadou B. Diallo provided useful comments on earlier drafts. The paper also benefited enormously from comments and suggestions by Núria Rodriguez-Planas, David Neumark, Amelie Constant and other participants at the IZA workshop on Labor Markets and Labor Policy in MENA Countries, as well as two anonymous referees. All remaining errors are, of course, my own. The views expressed in this paper do not necessarily represent those of the OECD, AfDB, or ONEQ.

Responsible Editor: David Neumark.

Received: 16 May 2013 Accepted: 10 July 2013

Published: 30 July 2013

\section{References}

Angel-Urdinola DF, Semlali A, Brodmann S (2010) Non-public provision of active labor market programs in ArabMediterranean countries: An inventory of youth programs. World Bank Social Protection Discussion Papers, World Bank, Washington DC, p 1005

Bartik TJ (2001) Jobs for the poor: Can labor demand policies help? Russell Sage Foundation, New York

Bartik TJ, Bishop JH (2009) The Job creation Tax credit: dismal projections for employment call for a quick, efficient, and effective response. Economic Policy Institute Briefing Papers, New York, p 248

Betcherman G, Olivas K, Dar A (2004) Impacts of active labor market programs: New evidence from evaluations with particular attention to developing and transition countries. World Bank Social Protection Discussion Papers, World Bank, Washington DC, p 0402

Betcherman G, et al. (2007) Global inventory of interventions to support young workers: synthesis report. World Bank Boone J, Van Ours JC (2004) Effective active labor market policies. IZA Discussion Papers, IZA, Bonn, p 1335

Burtless $G$ (1985) Are targeted wage subsidies harmful? evidence from a wage voucher experiment. Industrial and Labor Relations Review 39(1):105-115

Caliendo M, Kopeinig S (2008) Some practical guidance for the implementation of propensity score matching. Journal of Economic Surveys 22(1):31-72

Dubin J, Rivers D (1993) Experimental estimates of the impact of wage subsidies. Journal of Econometrics 56(1/2):219-42

Heinrich C, Maffioli A, Vázquez G (2010) A primer for applying propensity-score matching. IDB publications 8292. Inter-American Development Bank, Washington DC

ILO (2011) Tunisia: a new social contract for fair and equitable growth. Studies on growth with equity. International Institute for Labour Studies, Geneva

Immervoll H, Scarpetta S (2012) Activation and employment support policies in OECD countries. An overview of current approaches. IZA Journal of Labor Policy 1(9):1-20

Katz LF (1996) Wage subsidies for the disadvantaged. NBER Working Papers, NBER, Cambridge MA, p 5679

Kluve J (2006) The effectiveness of European active labor market policy. IZA Discussion Papers, IZA, Bonn, p 2018

Kluve J (2010) The effectiveness of European active labor market programs. Labour Economics 17(6):904-918

Leuven E, Sianesi B (2003) PSMATCH2: Stata module to perform full Mahalanobis and propensity score matching, common support graphing, and covariate imbalance testing. http://ideas.repec.org/c/boc/bocode/s432001.html

Marouani MA (2010) More jobs for university graduates: some policy options for Tunisia. Applied Economics Letters 17 (10):933-937

Martin JP (2000) What works among active labour market policies: evidence from OECD countries' experiences. OECD Economic Studies 30:79-113

Ministère de l'Emploi et de l'Insertion Professionnelle des Jeunes and World Bank (2009) L'Insertion des jeunes diplômés de l'Enseignement supérieur - promotion 2004 : analyse comparative des résultats de deux enquêtes (2005 et 2007). République Tunisienne, p 51565. http://www-wds.worldbank.org/external/default/WDSContent Server/WDSP/IB/2009/11/12/000020953_20091112162329/Rendered/PDF/515650ESWOP1111CHORapport0 Dynamique.pdf

Neumark D (2013) Spurring job creation in response to severe recessions: reconsidering hiring credits. Journal of Policy Analysis and Management 32(1):142-171

Neumark D, Grijalva D (2013) The employment effects of state hiring credits during and after the great recession. NBER Working Papers, NBER, Cambridge MA, p 18928

OECD (2005) Labour market programmes and activation strategies: evaluating the impacts. OECD employment outlook 2005. OECD Publishing, Paris

Premand P, et al. (2012) Entrepreneurship training and self-employment among university graduates: evidence from a randomized trial in Tunisia. World Bank Policy Research Working Papers, World Bank, Washington DC, p 6285

Rosenbaum PR, Rubin DB (1983) The central role of the propensity score in observational studies for causal effects. Biometrika 70(1):41-55

Van Reenen J (2003) Active labour market policies and the British New deal for the young unemployed in context. NBER Working Papers, NBER, Cambridge MA, p 9576

World Bank (2012) Evaluation stratégique du fonds national pour l'Emploi de la Tunisie. World Bank, Washington DC, Draft June 2012

doi:10.1186/2193-9004-2-9

Cite this article as: Broecke: Tackling graduate unemployment in North Africa through employment subsidies: A look at the SIVP programme in Tunisia. IZA Journal of Labor Policy 2013 2:9. 